\title{
Utilizing satellite data of several spectral ranges for modelling the processes of water and heat regime formation of vast territories
}

\author{
E. L. Muzylev ${ }^{1}$, Z. P. Startseva ${ }^{1}$, E. V. Volkova ${ }^{2}$, E. V. Vasilenko ${ }^{2}$ \\ ${ }^{1}$ Water Problems Institute, Russian Academy of Sciences, Moscow, 119333, Russia \\ ${ }^{2}$ State Research Centre of Space Hydrometeorology "Planeta", Moscow, 123242, \\ Russia \\ E-mail: muzylev@iwp.ru
}

\begin{abstract}
A method was developed for assessing soil water content $W$ (as basic indicator of water availability), evapotranspiration $E v$, and other water and heat regime (WHR) elements of agricultural regions during vegetation season (VS). The base of the method is the physicalmathematical model of land surface-atmosphere water and heat exchange adapted to satellitederived estimates of vegetation and meteorological characteristics (VMC). These estimates used as model parameters and input variables were obtained by thematic processing data from radiometers-scanners AVHRR/NOAA, SEVIRI/Meteosat-10, -11, -8, and MSU-MR/Meteor-M No. 2 in the visible and IR ranges. Soil surface moisture (SSM) estimates used to calculate $W$ were produced from measurements of scatterometer ASCAT/MetOp in the microwave range. The case study were carried out for forest-steppe territory of $227300 \mathrm{~km}^{2}$ located in the Black Earth Region of European Russia and for arid steppe territory of the Saratov and Volgograd Trans-Volga region of $66600 \mathrm{~km}^{2}$ for VS of 2016-2018. The main results of the study are: procedures to assimilate satellite-derived VMC estimates in the model were developed; the possibilities to use ASCAT-derived SSM estimates for calculating $W$ were confirmed; $W, E v$ and other WHR characteristic estimates were obtained for the named VS as distributions over the area under study.
\end{abstract}

Accepted: 15.09 .2020

DOI: 10.21046/2070-7401-2020-17-6-129-136

\section{Introduction}

Development of methods for assessing water resources of vast agricultural regions especially in conditions of their actual deficit gains in importance. The most effective tool to devise such method for a long time interval, such as vegetation season is at presence the physical-mathematical model of land surface-atmosphere water and heat exchange (WHE) LSM (Land Surface Model), intended for calculating soil water content $W$ (which is the main indicator of water availability), evapotranspiration $E v$ and other water and heat regime (WHR) elements of the territories under study [1]. Utilizing the satellite-derived values of the land surface (LS) and meteorological characteristics in the LSM significantly increases the accuracy of calculation of water and heat exchange components which is especially important for territories characterized by the lack or absence of ground-based observation data [2]. The foregoing determined the objective of the study as developing the method to estimate the named WHR elements of vast territories using space monitoring data. Satellite information was presented in the study by the measurement data from scanning radiometers AVHRR/NOAA, SEVIRI/geostationary Meteosat-10, $-11,-8$, and MSU-MR/Meteor-M No. 2 in the visible and IR ranges. The desired estimates of vegetation and meteorological characteristics were built by thematic processing 
these data. The soil surface moisture (SSM) was determined from the data measured by scatterometer ASCAT/MetOp in the microwave range [3]. The case study were the forest-steppe part of the Central Black Earth region (CBER) of European Russia containing 7 administrative regions of the Russian Federation of $227300 \mathrm{~km}^{2}$, mainly occupied by agricultural crops and dry steppe territory of the Saratov and Volgograd Trans-Volga region (the left-bank part of the Saratov and Volgograd regions) of $66600 \mathrm{~km}^{2}$ where agricultural production is possible only when watering.

The study carried out for vegetation seasons of 2016-2018 included: 1) development and improvement of procedures to assimilate satellite-retrieved estimates of meteorological and vegetation characteristics in the model; 2) verification of the possibilities to use ASCAT-derived SSM estimates when modeling the WHR of the areas under consideration; 3) obtaining, as the modeling result, the values of $W, E v, \mathrm{SSM}$ and other WHE characteristics and building their distributions over the region of interest for the named vegetation seasons.

\section{Brief description of the Land Surface Model (LSM)}

Physical-mathematical model LSM developed at the Water Problem Institute of Russian Academy of Sciences is the model of vertical water and heat transfer in the soil-vegetation-atmosphere system SVAT (Soil-Vegetation-Atmosphere-Transfer) adapted to satellite data on land surface and meteorological characteristics [1, 2]. LSM is intended for calculating WHR characteristics of the area under study in their dynamics: $W$ of the active soil layer, $E v$ (evaporation from bare soil and water transpiration by vegetation), vertical heat fluxes from LS, temperatures of soil surface $T_{g}$, vegetation cover $T_{f}$, and radiation land surface temperature (LST) $T_{s}$ as well as distributions of soil moisture and temperature by depth. The model is based on the vertical water transfer and heat equations for the active soil layer with boundary conditions at the upper and lower borders of the layer. Evaporation from soil surface and transpiration are determined using semi-empirical dependences on air humidity and temperatures (so-called bulk formulas). The $T_{g}$ and $T_{f}$ temperatures are found from the heat balance equations, respectively, for the soil and vegetation cover, neglecting the heat content of the latter. The radiation LST $T_{s}$ is calculated from the remainder of the equation for the long-wavelength part of the radiation balance, including atmospheric counterradiation. The model parameters are soil and vegetation characteristics. The first of them were determined using information from the HWSD (Harmonized World Soil Database) database. Part of vegetation characteristics were defined from ground-based observations, and vegetation cover fraction B and leaf area index LAI were estimated from satellite shooting data. The input model variables are air temperature, humidity and pressure, precipitation, cloudiness, and wind speed determined from standard term meteorological observations. Precipitation and LST were also estimated from satellite data.

From AVHRR, SEVIRI, and MSU-MR data there were retrieved estimates of the normalized vegetation index NDVI, LS emissivity E, B, LAI, soil surface temperature $T_{s g}$, air temperature at the vegetation level $T_{a}$, (taken as the vegetation surface temperature), effective LST $T_{\text {s.eff }}$, as well as cloudiness and precipitation. The values of all parameters and input variables were entered into the model in the form of area-distributions over the regions under study (they were calculated in the nodes of the computational grid with size of $3 \times 3$ pixels of the AVHRR IR channels $(\sim 7 \times 5 \mathrm{~km}))$. Also values of $W, E v$, and other WHR characteristics of the study area, as well as temperatures $T_{f}, T_{g}$, and $T_{s}$ were calculated at the grid nodes. The model was verified by comparing the values of $W$, calculated and measured at several agricultural meteorological stations of the each region as well as satellite-derived values of $E v$.

\section{Methods to assess meteorological and vegetation characteristics from satellite data}

The precipitation, LST, LAI and B values were calculated by thematic processing measurement data from all radiometers using the methods and technologies to build such estimates developed at the Scientific Research Center Planet.

Estimates of daily, ten-day and monthly precipitation sums were obtained for each pixel using the Multi Threshold Method (MTM) for detecting cloudiness and identifying its types, as well as allocating precipitation zones and determining their maximum intensity [4, 5]. The MTM is based on the implementation of the transition from assessing precipitation intensity to assessing their daily amounts. These sums are calculated by regression equations with measurement data from 5 AVHRR 
channels, 11 SEVIRI channels and 3 MSU-MR channels as well as their differences as predictors. Validation of the method for each sensor was carried out using observation data on daily precipitation amount at several agricultural meteorological stations of both CBER and Trans-Volga region. The probability of satellite detecting rainfall zones corresponded to the actual ones when compared with the ground-based observations was $75-85 \%$ for all sensors $[4,5]$. Thus, this technique was adapted to the areas under study. Examples of comparing time behavior of ground-measured and satellite-derived ten-day precipitation sums for vegetation seasons of 2017-2018 are given in figure 1. These examples demonstrate acceptable agreement between actual and calculated rainfall amounts.

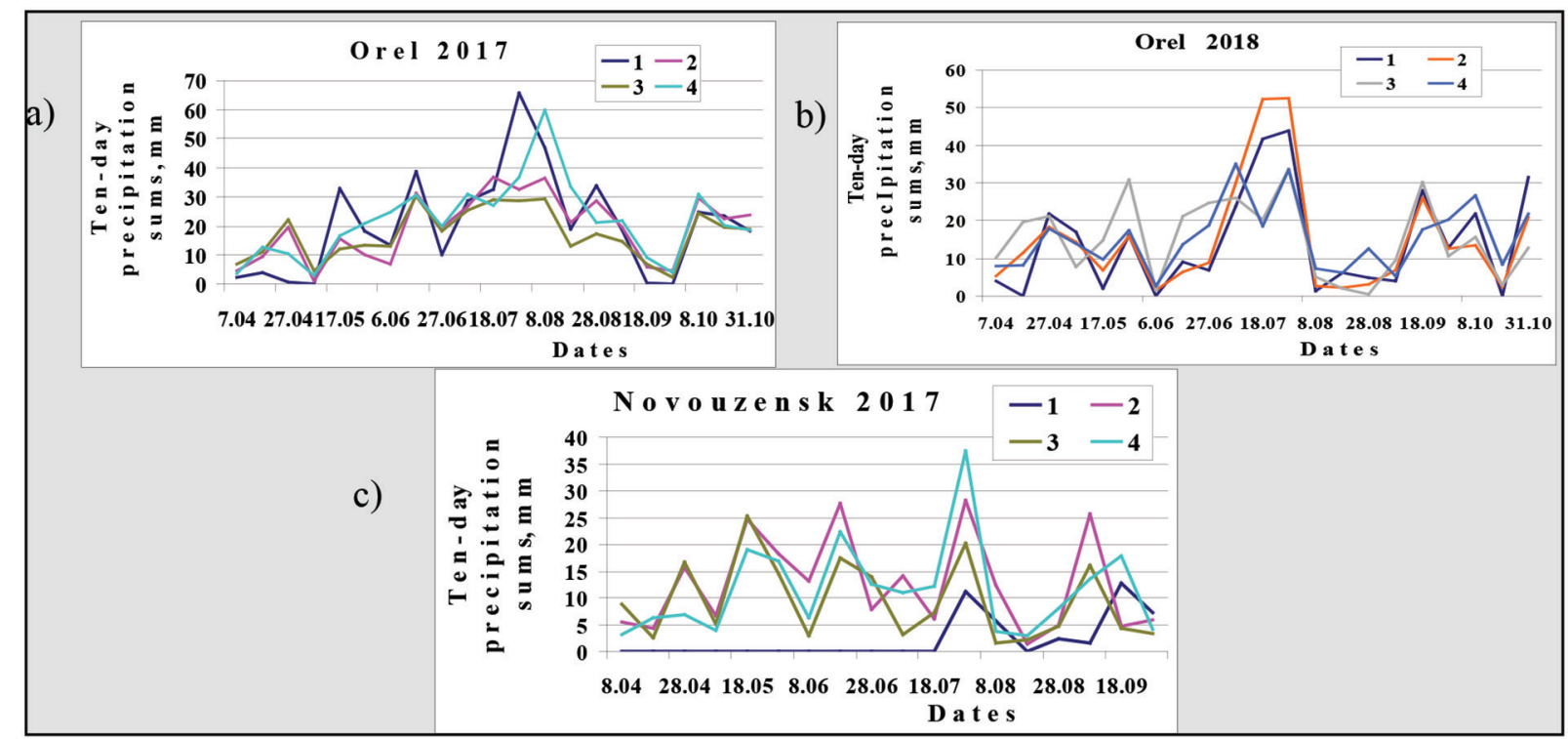

Figure 1. Ten-day precipitation sums at the agricultural meteorological stations Orel (CBER) for vegetation seasons of 2017 (a) and 2018 (b) and Novouzensk (Trans-Volga region) for season of 2017 (c): measured (1) and determined from SEVIRI (2), MSU-MR (3) and AVHRR (4) data.

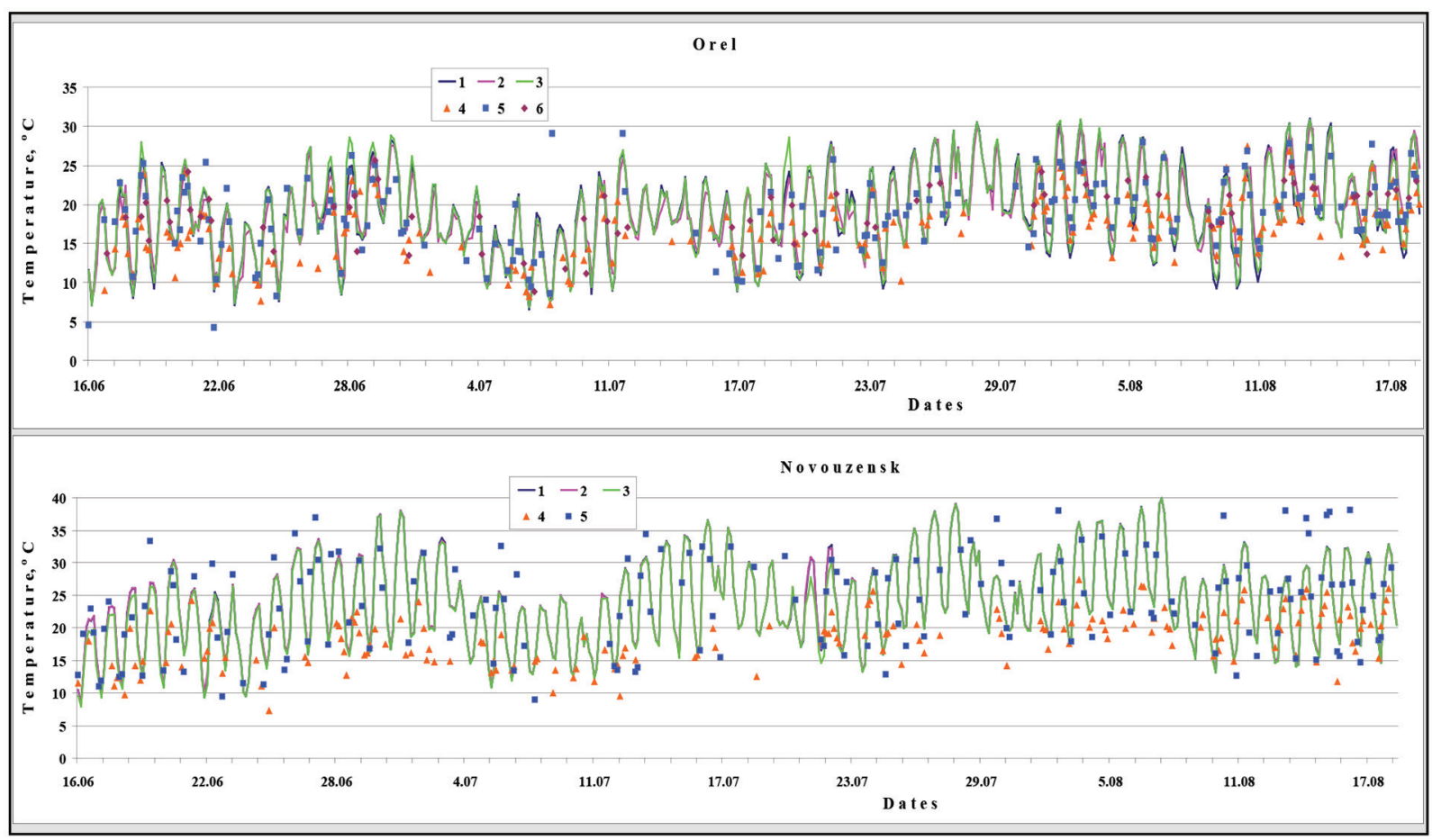

Figure 2. Vegetation surface temperature: modeled using ground-based (1) and ASCAT-derived (3) data, determined from SEVIRI (4), AVHRR (5) and MSU-MR (6) data and measured air temperature (2) at agricultural meteorological station Orel (CBER) (upper picture) and Novouzensk (Trans-Volga region) (lower picture) for vegetation season of 2017. 
Computational algorithm for estimating LSTs $T_{a}, T_{s g}$, and $T_{\text {s.eff }}$ was also developed on the basis of the MTM and debugged on the AVHRR and SEVIRI/Meteosat-9, -10 data for CBER [6] and then it was tested on the MSU-MR and SEVIRI/Meteosat-11, -8 data for both CBER and Trans-Volga regions. Values of $T_{s g}$ and $T_{a}$ were retrieved by the GSW (Generalized Split-Window) method [7] using the regression equations with satellite-measured radiation temperature from 11 and $12 \mu \mathrm{m}$ channels for cloudless pixels utilizing ground-observed data on $T_{f}$ and $T_{g}$ synchronous with satellite-derived ones. The correctness of LST estimates for named vegetation seasons built with the application of MTM from each radiometer data was verified through comparing their values among themselves, with ground-measured air temperature and with the results of model calculations using ground-based and satellite-derived temperature data. These comparisons were made by collating the time behaviour of all temperatures during vegetation season (figure 2). For the overwhelming majority of observation terms, the LST values are comparable in accuracy, except cases of significant local soil surface overheating in the second half of the day in hot summer months and, as a consequence, the excess of ground-based estimates over satellite-retrieved ones. Values of NDVI were calculated using standard albedo relationships, while values of LAI and B were assessed using empirical dependences on NDVI. The correctness of LAI and B estimates obtained from each sensor data was confirmed by comparing satellite-retrieved LAI time behaviour during vegetation season. The errors of determining B and LAI in these cases were about 15 and $20 \%$, respectively.

\section{Results of utilizing satellite-derived vegetation and meteorological characteristic estimates in the LSM} Developed and improved procedures to assimilate AVHRR-, SEVIRI-, and MSU-MR-retrieved estimates of LAI, B, LST, and precipitation in the LSM included: 1) verification of the reliability of all satellite-derived assessments by comparing them with each other and with ground-observed values; 2) replacement of ground-measured model parameters LAI and B by their satellite-derived estimates; 3) using assessments of daily precipitation sums and values of LSTs calculated from each sensor data as the input model variables instead of the corresponding ground-measured rainfall and temperatures; 4) accounting for the spatial and temporal variability of the fields of satellite-derived LAI, B, precipitation, and LST estimates providing by their entering into the model at each time step in all computational grid nodes.

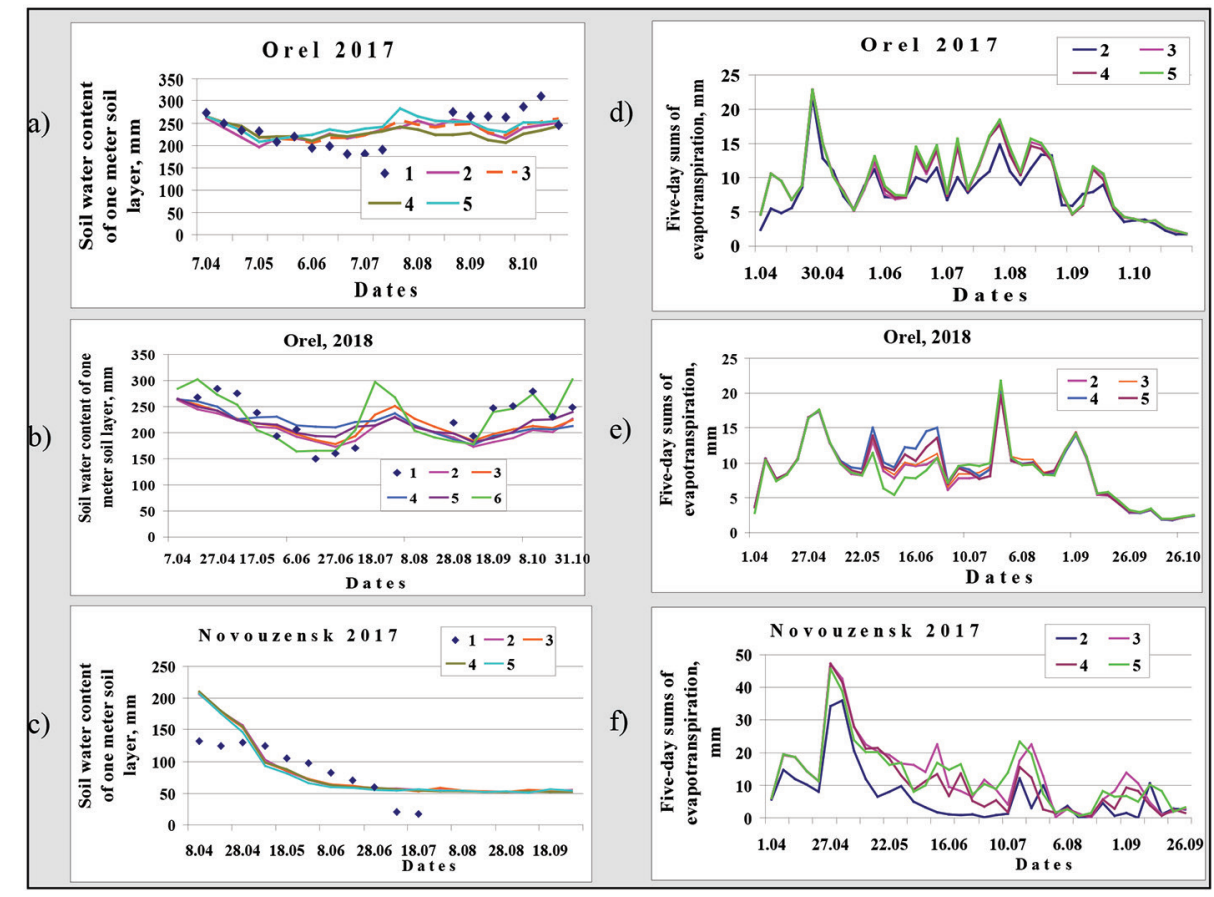

Figure 3. Soil water content (a)-(c) and evapotranspiration (d) -(f) at the agricultural meteorological stations Orel (CBER) for vegetation seasons of 2017 (a), (d) and 2018 (b), (f) and Novouzensk (Trans-Volga region) for vegetation season of 2017 (c), (f): measured (1) and modeled using ground-based (2), SEVIRI (3), MSUMR (4) and AVHRR-derived (5) rainfall estimates and when assessing soil evaporation utilizing ASCAT data (6). 


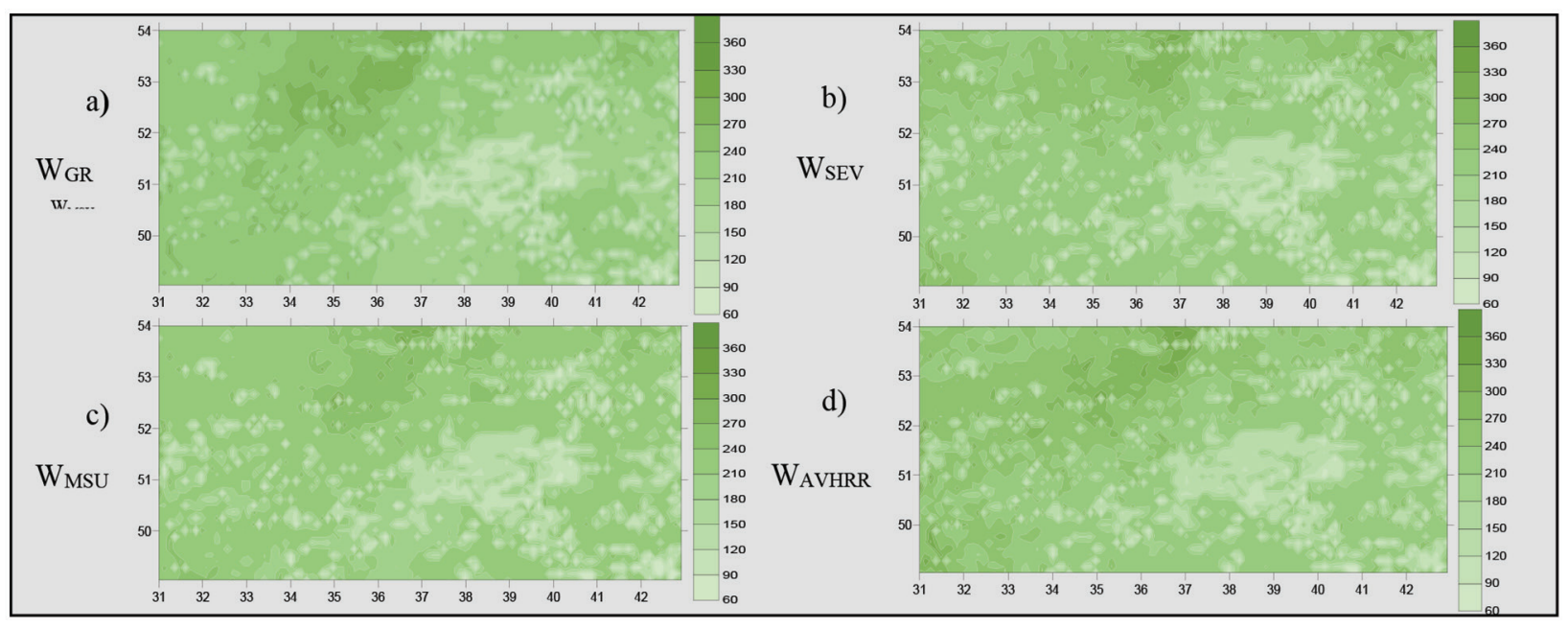

Figure 4. Soil water content of one meter soil layer, $\mathrm{mm}$, modelled using daily precipitation sum: groundmeasured $W_{\mathrm{GR}}$ (a), derived from SEVIRI/Meteosat-10 $W_{\mathrm{SEV}}$ (b), MSU-MR/Meteor-M No. $2 W_{\mathrm{MSU}}$ (c) and AVHRR $W_{\text {AVHRR }}($ d) data distributed over study SBER area on May 29, 2017.

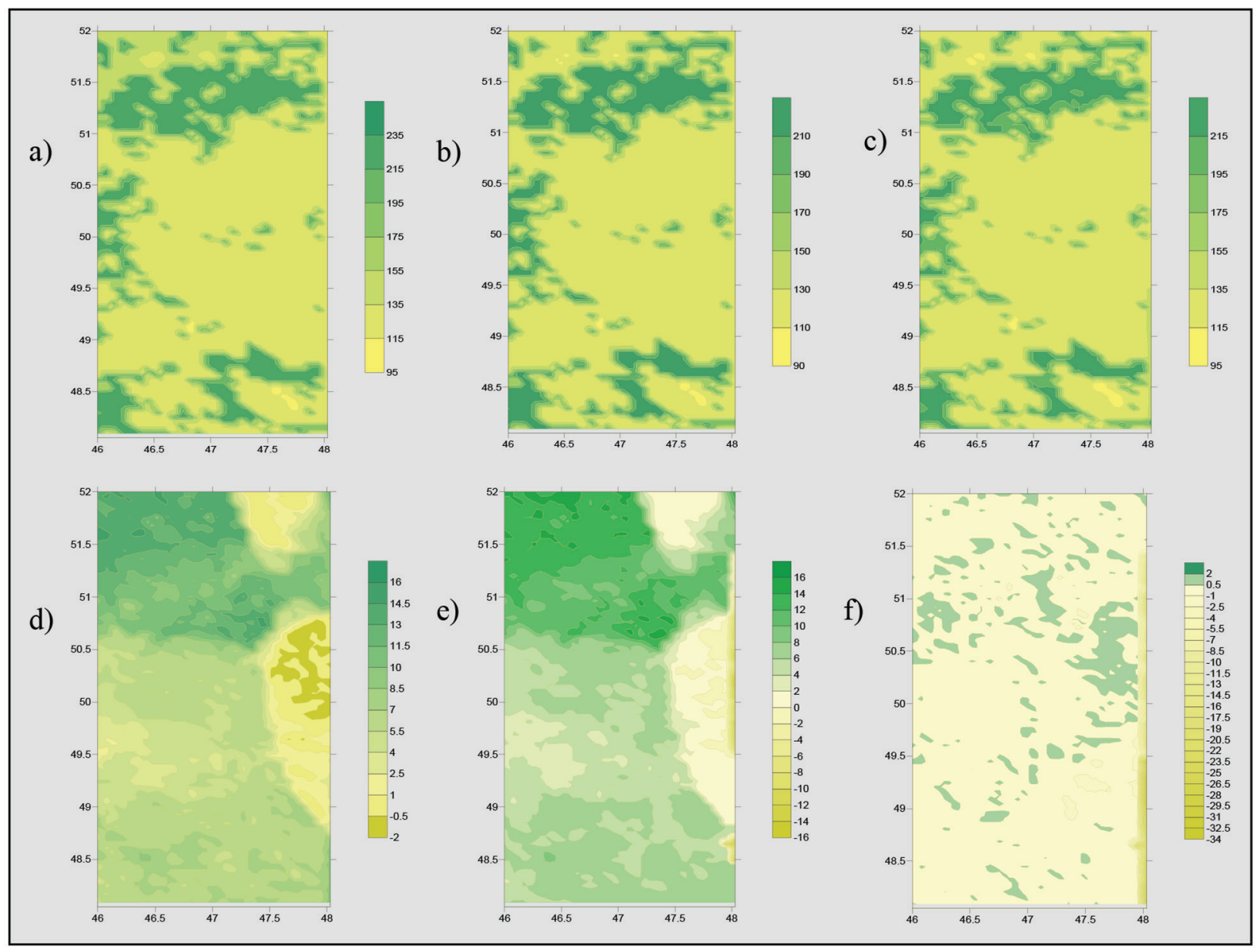

Figure 5. Soil water content of one meter soil layer, mm, modelled using daily rainfall sum: ground-measured $W_{\mathrm{GR}}(\mathrm{a})$, derived from SEVIRI/Meteosat-10 $W_{\mathrm{SEV}}(\mathrm{b})$, and AVHRR $\mathrm{W}_{\mathrm{AVHRR}}$ (c) data and their differences $W_{\mathrm{GR}}-W_{\mathrm{SEV}}(\mathrm{d}), W_{\mathrm{GR}}-W_{\mathrm{AVHRR}}(\mathrm{e})$, and $W_{\mathrm{SEV}}-W_{\mathrm{AVHRR}}(\mathrm{f})$ distributed over Trans-Volga region area on July 30,2017 .

In the absence of satellite-retrieved precipitation and LST estimates in some nodes the values of these quantities, as well as air humidity, were determined by interpolating standard meteorological observation data. The correctness of the made replacements was confirmed by the above-described 
results of comparing the time behaviors of LAI, B, precipitation and LST during considered vegetation seasons; 5) carrying out the calculation of $W, E v$ and other WRR characteristics of the regions under study using built satellite-derived LAI, B, LST and precipitation estimates for vegetation seasons of 2016-2018. The reliability of modelled $W$ and $E v$ values for all variants of LAI, B, precipitation and LST estimation from each sensor data was confirmed by the results of their comparison between themselves and with ground-measured ones. The discrepancy of $W$ and $E v$ estimates for overwhelming majority of measurement terms during above vegetation seasons did not exceed 15 and $25 \%$, which corresponds to the generally accepted error of determining $W$ and $E v$ values (figure $3 \mathrm{a}-\mathrm{c}, \mathrm{d}-\mathrm{f}$ ).

The fields of the calculated values of $W$ and $E v$, latent and sensible heat fluxes, three types of LSTs, as well as distributions of soil moisture and temperature by depth, built for the regions under study, are the final modelling results. Comparing the fields of differences of $W$ values calculated using satellitederived and ground-based rainfall amounts shown that the errors of the presented $W$ estimates were within the above limits (figure $4 a-d, 5 a-f)$.

\section{Results of ASCAT-derived soil surface moisture estimation and their utilization when modelling water and heat regimes of the area under study}

In the paper there is described the possibility of using SSP estimates from scatterometer ASCAT/MetOp data measured in microwave range to simulate WHR of agricultural areas. The results of such measurements are expressed as percentage from 0 to 100, which corresponds to the absence of soil moisture or its complete saturation. The obtained estimates are converted into the moisture of upper soil layer $(0-3 \mathrm{~cm})$ in volumetric units $\left(\mathrm{cm}^{3} / \mathrm{cm}^{3}\right)$, multiplying SSM by the porosity values. The correctness of such estimates for areas under consideration was verified through their comparison with the results of SSM simulation for above vegetation seasons: 1) using ground-based observation data; 2) when presetting the initial soil moisture profile utilizing ASCAT data, which increases the accuracy of SSM calculations; 3) when estimating soil evaporation using ASCAT data at each time step, which further increases the accuracy of calculating SSM (figure 6,7).

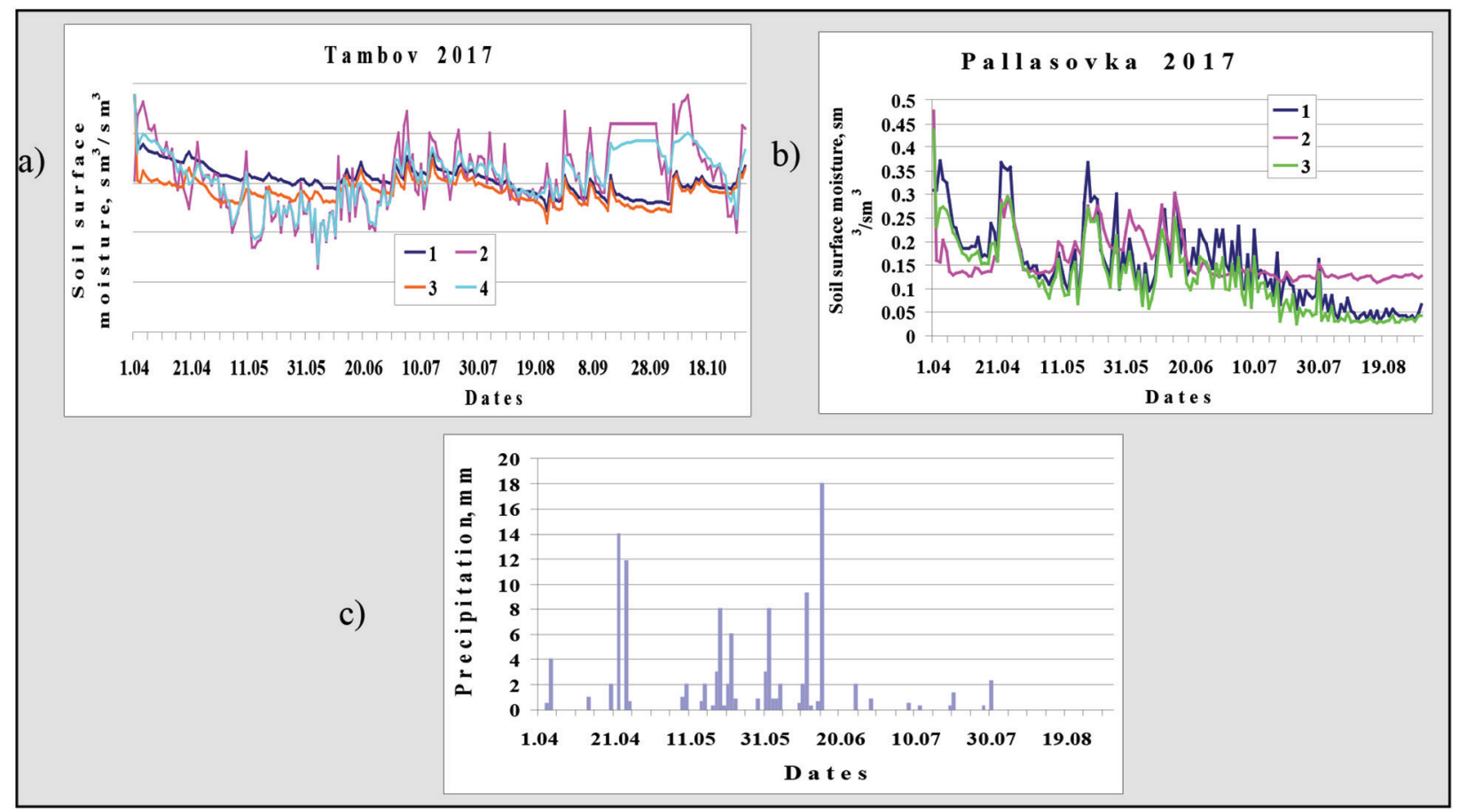

Figure 6. Relative soil surface moisture for vegetation season of 2017 at agricultural meteorological stations Tambov (CBER) (a): modeled using ground-based data (1), obtained directly from ASCAT data (2), modelled with preset initial soil moisture profile using ASCAT data (3) and evaporation values calculated accounting for ASCAT data (4), and Pallasovka (Trans-Volga region) (b): obtained directly from ASCAT data (1), modeled using ground-based data (2) and evaporation values calculated accounting for ASCAT data (3). Bottom picture represents precipitation at Pallasovka station. 


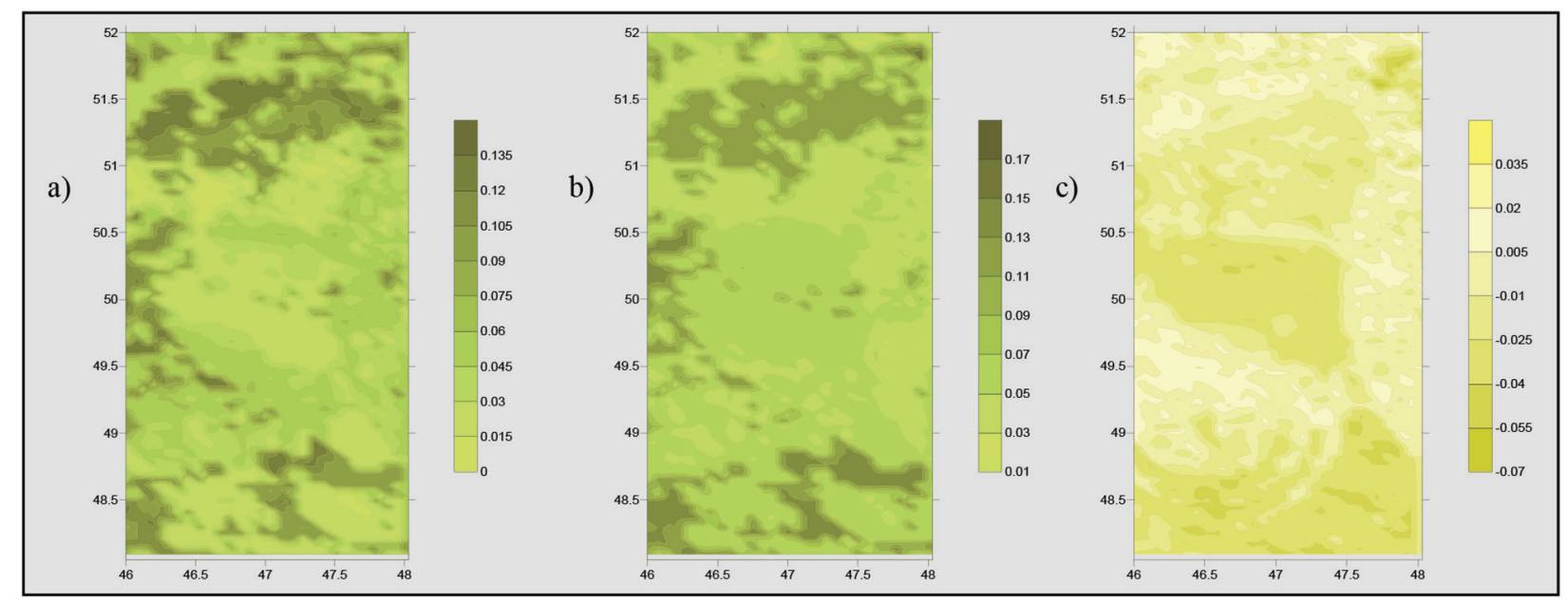

Figure 7. Moisture of surface soil layer $(0-3 \mathrm{~cm}), \mathrm{cm}^{3} / \mathrm{cm}^{3}$, modelled using ground-based data (a), obtained from ASCAT data (b) and their differences (c) for Trans-Volga region area on June 30, 2017.

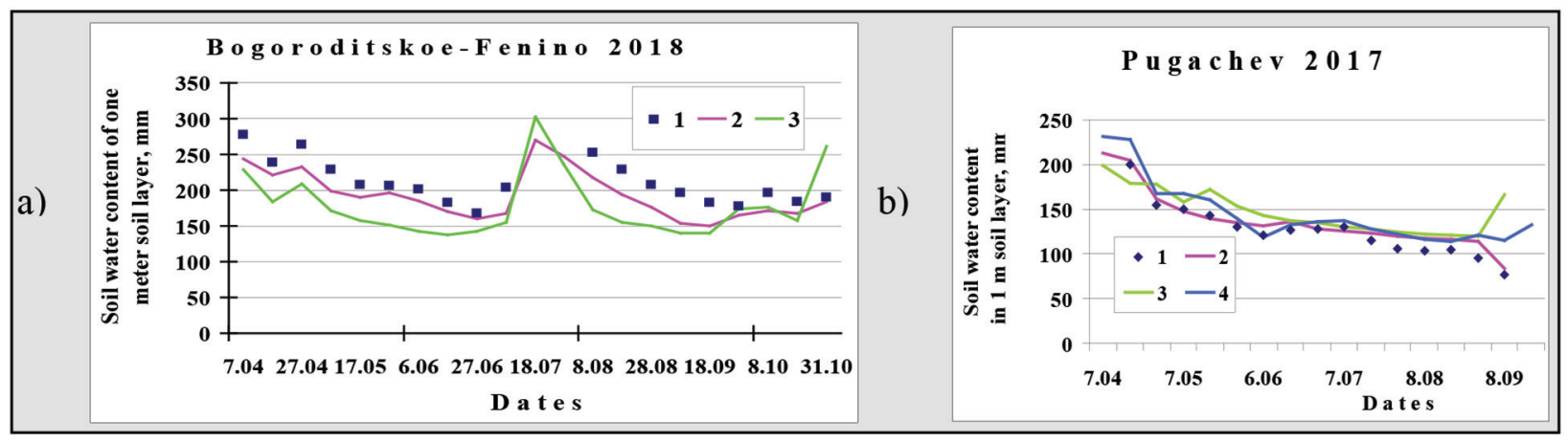

Figure 8. Soil water content of one meter soil layer at agricultural meteorological stations Bogoroditskoe-Fenino (a) and Pugachev (b) for vegetation seasons of 2018 and 2017, accordingly: measured (1) and modelled using ground-observed data (2), evaporation values calculated with account for ASCAT data (3), and initial soil moisture profiles defined from ASCAT data (4).

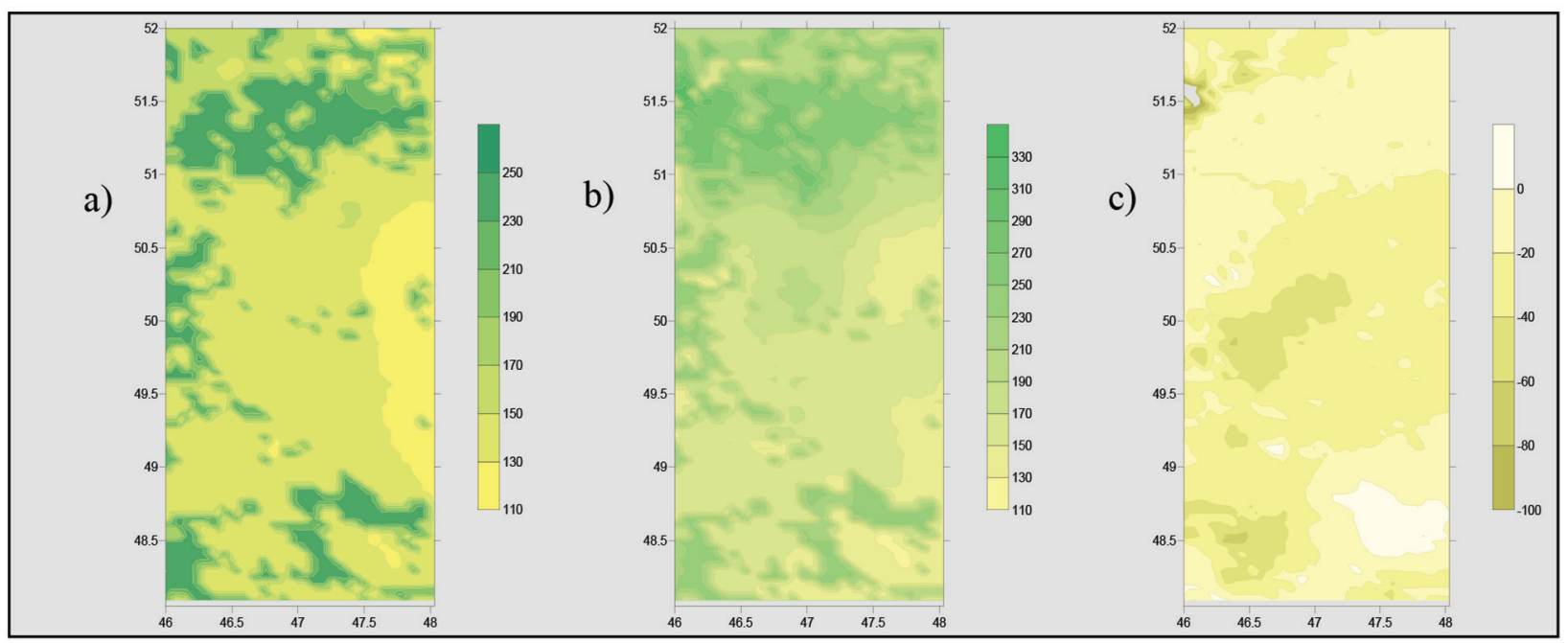

Figure 9. Distributions of soil water content over Trans-Volga region area on June 25, 2017: modelled using ground-based data (a), and soil surface moisture estimates from ASCAT data (2) and their difference (c).

The adequacy of the ASCAT data allows them to be used in the LSM for calculating values of $W$. Analysis of the differences of $W$ values for vegetation seasons, calculated under initial conditions based on different ASCAT-derived SSM estimates showed that in the first half of the season (approximately until the end of grain ripening), the greatest accuracy of calculating $W$ is ensured by accounting for 
ASCAT data when assessing soil evaporation, while in its second half calculations using direct ASCAT data are more accurate (figure 8).

Comparison of the fields of modelled $W$ values for the areas under study also demonstrated increasing the accuracy of estimation $W$ when using ASCAT data to preset initial soil moisture profiles for such calculations (figure 9).

\section{Conclusions}

The main result of the study is the developed method to estimate soil water content $W$, evapotranspiration $E v$ and other water and heat regime (WHR) characteristics during vegetation season for agricultural region areas with different conditions of moistening.

The method is based on the physical-mathematical model of land surface-atmosphere interaction LSM (SVAT) utilizing satellite data on land surface and meteorological condition.

The technologies to retrieve estimates of vegetation and meteorological characteristics from meteorological satellite data in visible and IR ranges as well as procedures to assimilate these estimates in the model were developed and improved.

The possibility was shown to use soil surface moisture estimates obtained from satellite data in the microwave range for calculating values of $W$ during vegetation season

Values of $W, E v$ and other WHR characteristics of the regions for vegetation seasons of 2016-2018 were calculated using the LSM. Their estimation errors did not exceed generally accepted values. These estimates being the final result of the simulation are presented as distributions over the areas under consideration.

\section{Acknowledgements}

The study was carried out in the framework of the State Program No. AAAA-A18-118022090056-0 (No. 0147-2018-0001).

\section{References}

[1] Muzylev E., Startseva Z. P., Uspensky A. B., Volkova E. V., Modeling Water and Heat Balance Components for Large Agricultural Region Utilizing Information from Meteorological Satellites, Water Research, 2018, Vol. 45(5), pp. 672-684.

[2] Startseva Z., Muzylev E., Volkova E., Uspensky A., Uspensky S., Water and heat regimes modelling for a vast territory using remote-sensing data, Intern. J. Remote Sensing, 2014, Vol. 35(15), pp. 5775-5799.

[3] Wagner W., Hahn S., Kidd R., Melzer Th., Bartalis Z., Hasenauer St., Figa-Saldaña Ju., de Rosnay P., Jann Al., Schneider St., Komma J., Kubu G., Brugger K., Aubrecht Ch., Züger J., Gangkofner U., Kienberger St., Brocca L., Wang Y., Blöschl G., Eitzinger J., Steinnocher K., The ASCAT Soil Moisture Product: A Review of its Specifications, Validation Results, and Emerging Applications, Meteorologische Zeitschrift, 2013, Vol. 22(1), pp. 5-33.

[4] Volkova E., Automatic estimation of cloud cover and precipitation parameters obtained by AVHRR NOAA for day and night condition, Sovremennye problemy distantsionnogo zondirovaniya Zemli iz kosmosa, 2013, Vol. 10(3), pp. 66-74.

[5] Volkova E., Estimation of precipitation amount using SEVIRI/METEOSAT-9 and AVHRR/NOAA data for the European territory of Russia, Sovremennye problemy distantsionnogo zondirovaniya Zemli iz kosmosa, 2014, Vol. 11(4), pp. 163-177.

[6] Volkova E., Uspensky S., Land surface, land air and effective temperature estimation for territories of Southern European Russia based on satellite data, Sovremennye problemy distantsionnogo zondirovaniya Zemli iz kosmosa, 2016 Vol. 13(5), pp. 291-303.

[7] Product user manual. Land Surface Temperature (LST). SAF/LAND/IM/PUM_LST/2.5, 2010, Vol. 2.5, 49 p. 